\title{
SIMULATION AND CONTROL OF A SPIDER CRAB BIOMECHANICAL MODEL
}

\author{
Rita Rynkevic ${ }^{1}$, Manuel F. Silva ${ }^{2}$, Arcelina M. Marques ${ }^{1}$ \\ ${ }^{1}$ Physics Department, School of Engineering - Polytechnic of Porto, \\ Rua Dr. António Bernardino de Almeida, 4200-072 Porto, Portugal \\ ${ }^{2}$ INESC TEC - INESC Technology and Science (formerly INESC Porto) and ISEP/IPP - School of Engineering, \\ Polytechnic Institute of Porto, \\ Rua Dr. António Bernardino de Almeida, 4200-072 Porto, Portugal \\ r.rynkevic@gmail.com, \{mss,mmr $\}$ isep.ipp.pt
}

\begin{abstract}
One line of research and development in robotics receiving increasing attention in recent years is the development of biologically inspired robots. The idea is to gain knowledge of biological beings and apply the knowledge thus acquired to implement the same methods of locomotion (or at least use the biological inspiration) on the machines we build. It is believed that this way it is possible to develop machines with capabilities similar to those of biological beings in terms of locomotion skills and energy efficiency. One way to better understand the functioning of these systems, without the need to develop prototypes with long and costly development, is to use simulation models. Given these ideas, this work concerns the study of the biomechanics of the spider crab, using the SimMechanics toolbox of Matlab/Simulink. This paper describes the anatomy and locomotion of the spider crab, its modeling and control and the locomotion simulation of a crab within the SimMechanics environment.
\end{abstract}

\section{KEY WORDS}

Spider crab, locomotion, biomechanics, SimMechanics, modeling, simulation.

\section{Introduction}

In recent years, significant advances have been made in robotics, artificial intelligence and others fields that allow creating bio inspired machines. Scientists and engineers are using many of animals' performance characteristics for these advances.

Developing biologically inspired robots requires understanding the biological models, as well as advancements in analytical modeling, graphic simulation and the physical implementation of the related technology. The research and engineering areas that are involved with the development of biologically inspired robots are multidisciplinary and they include materials, actuators, sensors, structures, functionality, control, intelligence and autonomy.
It is straightforward to see that even the most advanced robots reveal much inferior performances than their biological counterparts. Animal locomotion is much more versatile, efficient and elegant and, therefore, it is reasonable to consider biological systems in order to apply their schemes in the design and control of mechanical robots. For these reasons, there has been an investment in the development of robots that are mimics, as close as possible, of animals. There exist already (or are under development) mechatronic mimics of varied animals such as the cricket [1], the chicken [2], the gorilla $[3,4]$, the dog [4,5], the Hermann Turtle [6] and the lobster [7].

Due to the desire to develop a walking robot able to move on the seashore, in sandy and rocky bottoms, it was decided to study animals that present good locomotion abilities in these terrains. The spider crab become a good choice for inspiration among the different animals analyzed, due to its living environment (that fits with the purpose of the intended study) and also since the structure of its body and its anatomy seemed interesting, as well as the possibility to easily get the needed specimens for studies. Based on these ideas, the aim of this study is to conduct a simulation study of the biomechanics of the spider crab.

The remainder of this paper is organized as follows. Section two presents a brief description of the spider crab and section three the determination of its biometric indices. Sections four and five present the kinematic and the dynamic model, respectively. Section six presents several simulation results obtained with the implemented model. Finally, section seven presents the main conclusions of this study and some ideas for future developments.

\section{Spider Crab (Maja brachydactyla)}

Maja brachydactyla (see Figure 1) (the European spider crab, spiny spider crab), a kind of edible crab belonging to the family Majidae arthropod decapod, is a species of migratory crab found in the north-east Atlantic and the 
Mediterranean Sea [8]. Maja brachydactyla also supports commercial fisheries in northern Spain (Galicia), Portugal and in the Adriatic Sea [8].

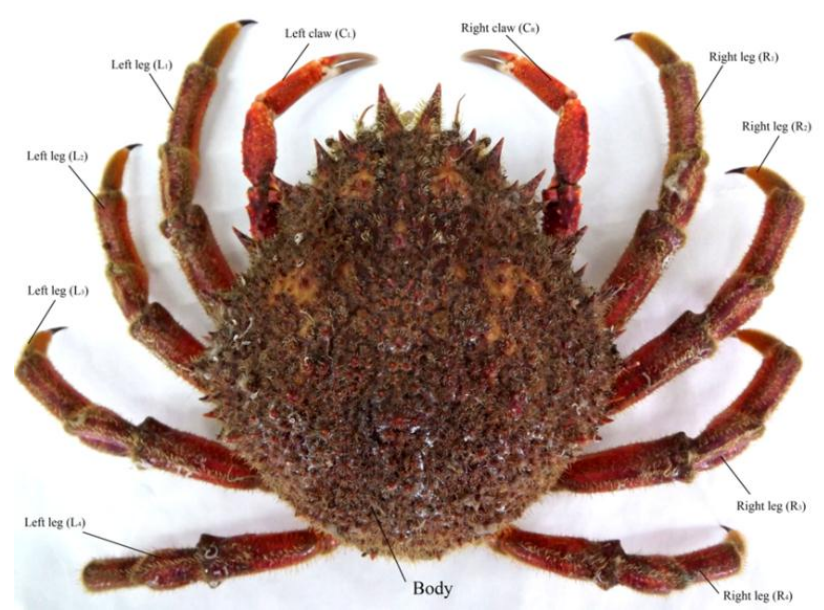

Figure 1. Photo of Maja brachydactyla with the legs numbered according to the nomenclature used on this work

This crab's carapace presents a cord form and an irregular surface (with many nozzles), in general, coated with algae, and six spines on the longer side edges and two divergent large spikes at the front. It has five pairs of legs of which two strong clamps. Usually lives in sandy and rocky bottoms, where it hides among vegetation or in cracks. It feeds on algae, mollusks and echinoderms [8]. The spines are a protection against predators, but can also be dangerous to the unwary swimmers, if a carapace is trodden on. Fortunately they are not poisonous like some organisms such as the spider fish.

\section{Determination of Biometric Indices}

Measurements of the crabs were made in Estação Litoral da Aguda (ELA) in one of the laboratories. The used materials were 4 spider crabs (two of them were dead and two alive). Length and weight of each animal's segment (see Figure 2) were measured and, by taking the ratio of each segment, the average indices were calculated [9].

\subsection{Locomotion of Maja brachydactyla}

This section deals with the biomechanics of walking and locomotion. Walking is an automatic motor action which occurs as a result of complex coordinated activity of the skeletal muscles of the trunk and extremities. The motion of the individual units of the free leg is determined not only by muscle contraction but also by inertia [10].

A chronogram is a schedule displaying on a chart, for each operation, the amount of time it takes, and with all operations arranged in series according to their occurrence.

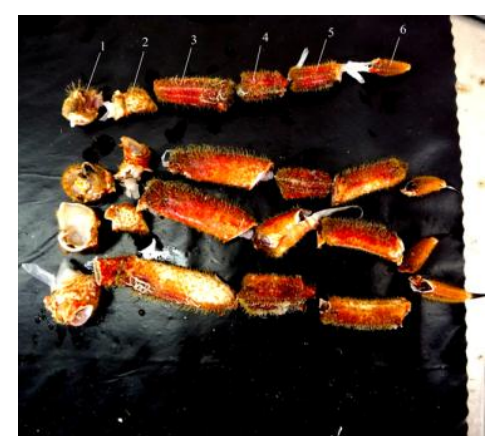

Figure 2. Legs of Maja brachydactyla, cut in the segments

Videos were used to make the chronograms of the walking locomotion of the crabs, which were made by filming live crabs in an aquarium in ELA (see Figure 3).

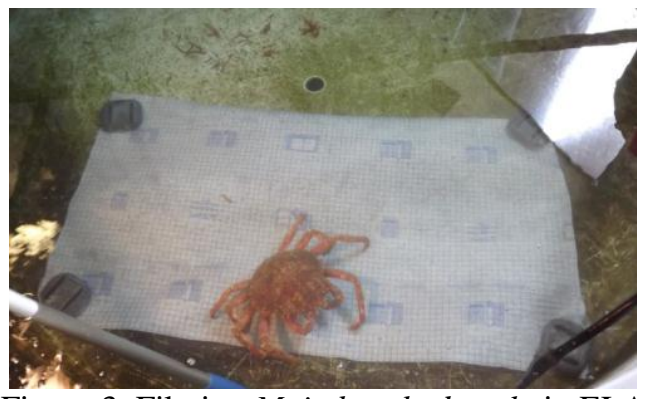

Figure 3. Filming Maja brachydactyla in ELA

Figure 4 presents a chronogram depicting the locomotion of the spider crab sideways. The shaded parts of the chronogram represent the periods of time when a leg is on the ground (the leg support phase); the white ones represent the periods of time when the legs make movements in the air (the leg transfer phase).

\begin{tabular}{|l|l|l|l|l|l|l|l|l|}
\hline & $1 \mathrm{sec}$ & $2 \mathrm{sec}$ & $3 \mathrm{sec}$ & $4 \mathrm{sec}$ & $5 \mathrm{sec}$ & $6 \mathrm{sec}$ & $7 \mathrm{sec}$ & $8 \mathrm{sec}$ \\
\hline$R_{4}$ & & & & & & & & \\
\hline$L_{4}$ & & & & & & & & \\
\hline$R_{3}$ & & & & & & & & \\
\hline$L_{3}$ & & & & & & & & \\
\hline$R_{2}$ & & & & & & & & \\
\hline$L_{2}$ & & & & & & & & \\
\hline$R_{1}$ & & & & & & & & \\
\hline$L_{1}$ & & & & & & & & \\
\hline
\end{tabular}

Figure 4. Chronogram of a walking crab locomotion

The chronogram presented in Figure 5 was made using the same video, with the crab also moving sideways. The change of colors in this chronogram allows an easy interpretation of the movement of the legs during a time interval of one second.

Figure 6 shows the trajectory of the left leg $\left(L_{3}\right)$ during a complete locomotion period (transfer phase plus support phase). First, the crab moves the leg up by rotating the "hip" joint; after this, starts the movement of the "knee" joint and, finally, using the "hip" joint, the crab moves the leg down and puts the foot on the ground. After this motion, the leg pushes the body and the crab "moves" the body sideways. 


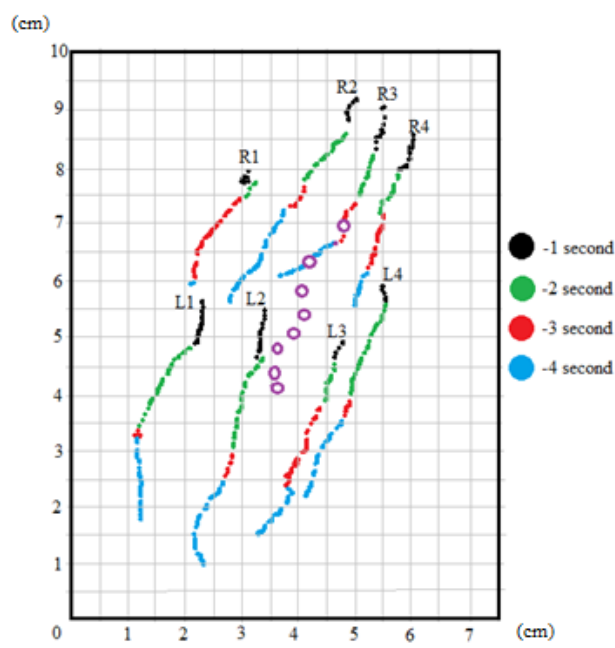

Figure 5. The chronogram of normal walking of Maja brachydactyla (scale 1:5)

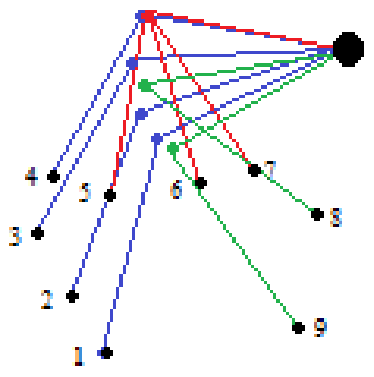

Figure 6. Locomotion of the leg during one period of locomotion

Crabs crawl along the terrain by using four pairs of legs. Crabs bend and unbend their legs consistently, and the same pair of left and right leg never operates simultaneously [11]. The leg consists of a series of movable articulated elements, whose mass is reduced towards the distal end. All joints allow movements around the $z$ and $y$ axis; this leads to leg flexion and rotation in plane. While walking the center of gravity of the crab is moving almost horizontally.

\section{Kinematic Model}

Most walking robots are very complex mechanical systems, displaying variable structures and different number of legs. The available options in legged robots are enormous, with configurations varying among, for example, 2 legs (biped), 4 legs (quadruped), 6 legs (hexapod) and 8 legs (octopod) like spiders.

In this paper is described the modeling and simulation of the spider crab, which has 8 legs (an octopod configuration).

\subsection{Number of degrees of freedom}

The number of degrees of freedom in a mechanical system is the number of independent parameters defining the position of all elements of the system. Figure 7 presents the equivalent mechanism of a spider crab leg (simple kinematic scheme).

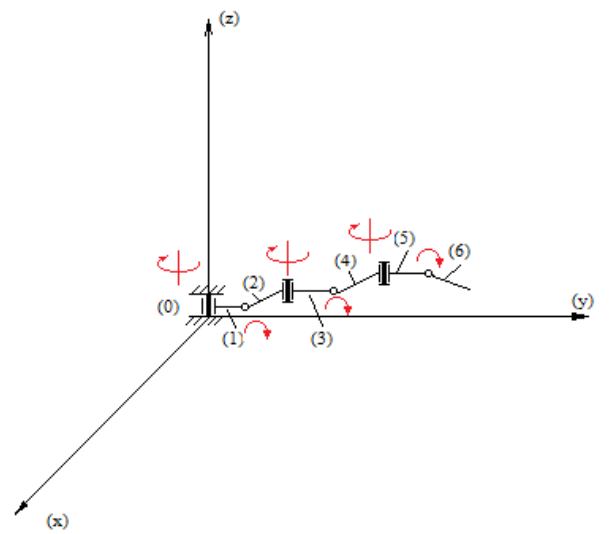

Figure 7. Equivalent mechanism of a spider crab single leg

To determine the number of degrees of freedom of a spatial mechanisms, the Malyshev formula (1) applies [12]:

$$
S=6 n-5 p_{1}-4 p_{2}-3 p_{3}-2 p_{4}-p_{5}
$$

Where:

$n$ - number of mobile units,

$p_{1}$ - number of a one-mobile $(S=1)$ kinematic pairs,

$p_{2}$ - number of two-mobile $(S=2)$ kinematic pairs,

$p_{3}-$ number of three-mobile $(S=3)$ kinematic pairs,

$p_{4}$ - number of four-mobile $(S=4)$ kinematic pairs,

$p_{5}-$ number of five-mobile $(S=5)$ kinematic pairs.

In a spider crab leg there are 6 revolute joints that make rotational movements about the $z$ and $x$ axis, leading to the number $n$ (number of mobile units) equal to 6 .

During the development of this work the kinematic scheme of the crab's legs was changed. The first and second segments from each leg were connected in one, and all joints were changed to revolute about $z$ axis. This is due to the fact that the first and second segments of the spider crab legs are too small $(\approx 12 \mathrm{~mm})$ and present a small range of motion $\left(\approx 20^{\circ}\right)$. Therefore, it was considered that they would be difficult to implement in a real robot. However, it was also verified in the simulations that these changes do not make a significant difference on the crab's locomotion. The masses and lengths of the remaining segments and body were not changed, and the data was taken as being the real one.

Figure 9 shows the new (simplified) kinematic model of a crab's leg. For this case the leg of the spider crab model has 5 degrees of freedom. 


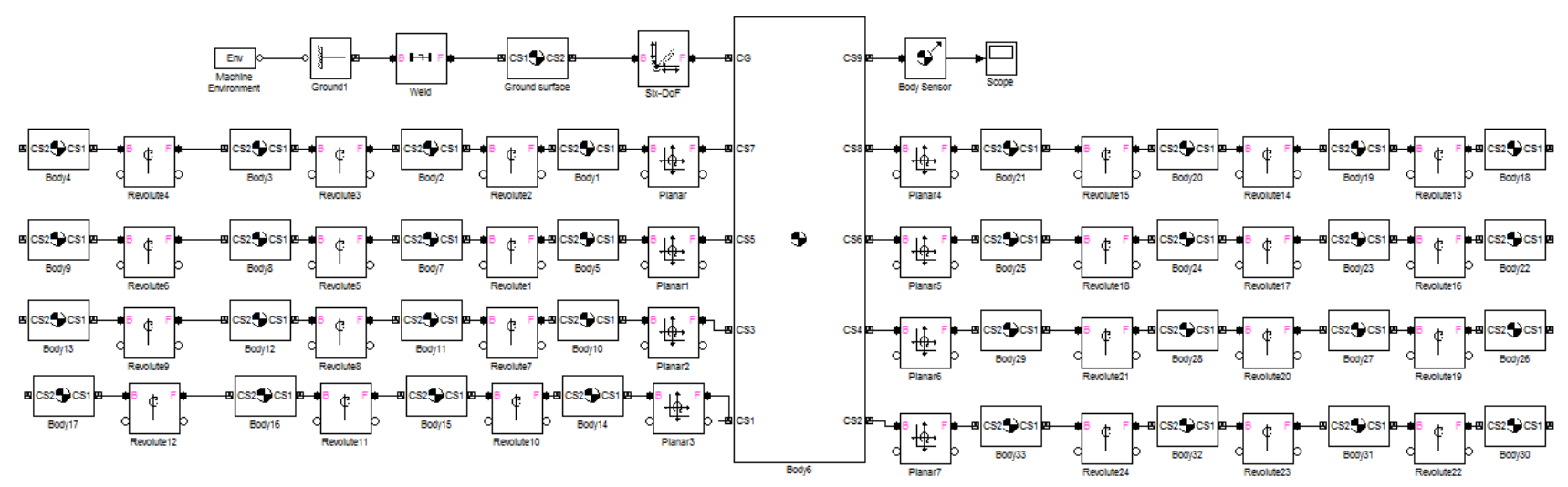

Figure 8. The kinematic model of the crab

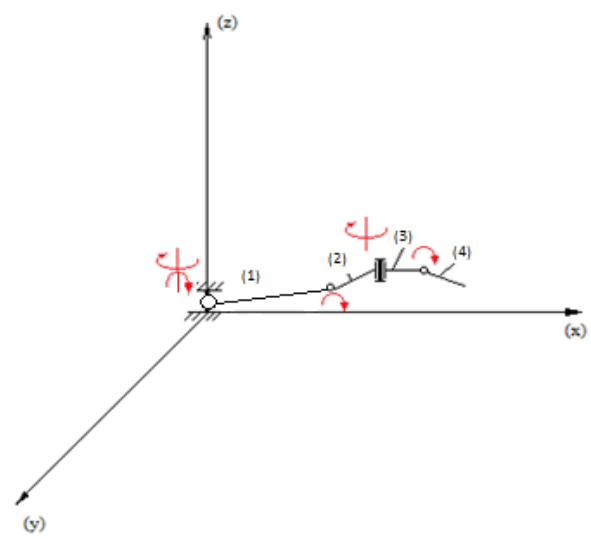

Figure 9. Kinematic scheme of a spider crab single leg (simplified mechanism)

\subsection{SimMechanics kinematic model}

SimMechanics is a library package (toolbox) of Simulink, running on the MATLAB environment, designed to simulate the mechanical motion of solids. Its main purpose is to model the spatial movements of solid-state machines in the engineering design stage, using the laws of theoretical mechanics $[13,14]$.

All legs of the crab were modeled in the same way, and were connected to the body through revolute joints, as presented in Figure 8. The model presented in this figure is in its simplest form, without sensors, actuators, and control system.

\subsection{SolidWorks model}

SolidWorks was used to model the geometry of the Spider crab. The general purpose of SolidWorks is the provision of through the process of design, engineering analysis and manufacture of products of any complexity and purpose. In this work, SolidWorks was used to draw all single parts of the crab's body, and latter connect all parts in one model (see Figure 10). This model is made using original data and has a geometric dimension equal to the real size of the crab measured in ELA.

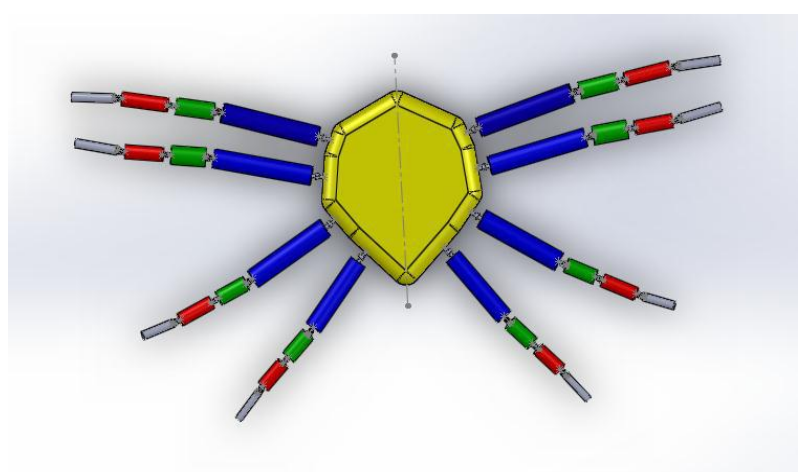

Figure 10. SolidWorks model of the crab

\section{Dynamic Model and Visualization}

In order to make a dynamic simulation the SimMechanics toolbox of Matlab Simulink was also used. The dynamic model is based on the kinematic model, and on the real measurements of the spider crabs. This means that the variables length, radius and mass of the legs and body of the robot are parametrically programmed in the dynamic model.

\subsection{SimMechanics dynamic model}

The "Robot Kinematics" block model, shown in Figure 12, is based on the kinematic model made in SimMechanics. Here the gray Body block represents the body of the crab, the eight blue subsystems represent legs, and the green subsystems are ground contact blocks. The ground is fixed at $z=0$ and the position of the robot center of gravity is connected through a 6 DOF block to the ground. 

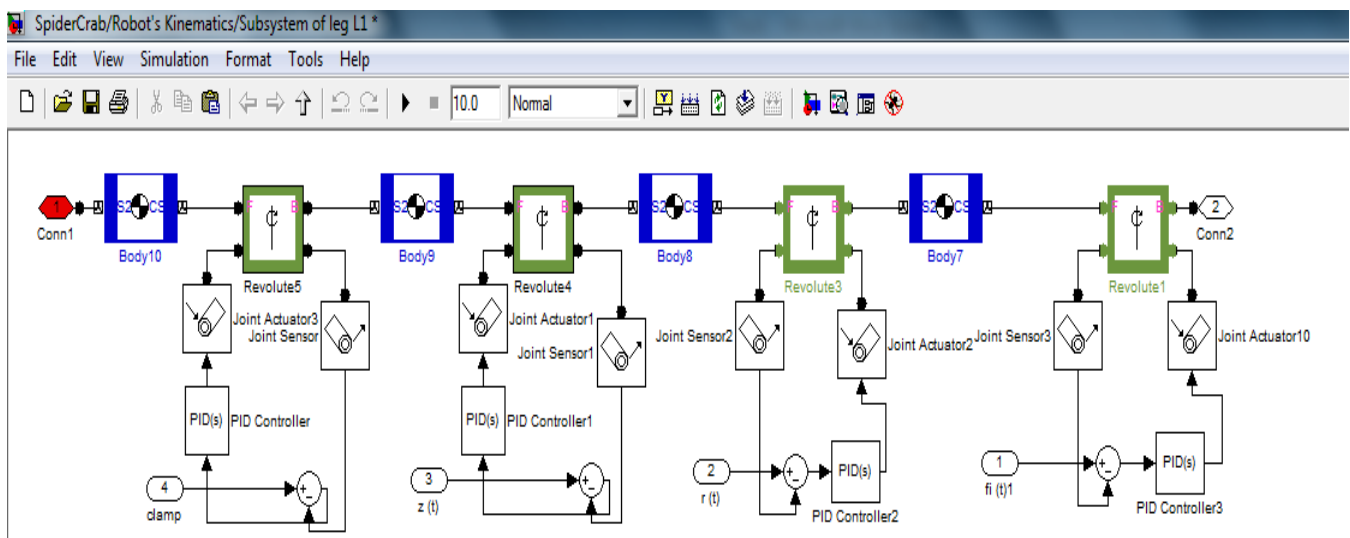

Figure 11. Dynamic model of a crab's leg in SimMechanics

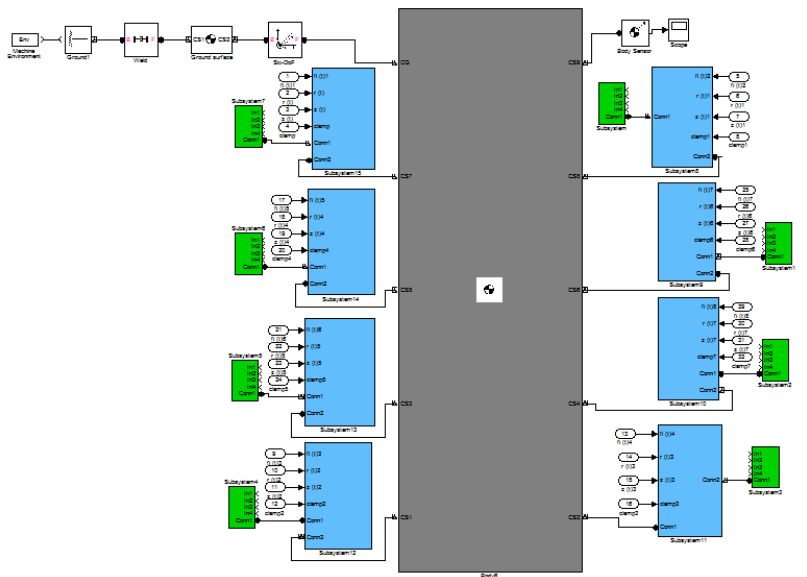

Figure 12. SimMechanics representation of the crab

Each leg has the same structure, being one of the dynamic models of a leg presented on Figure 11. Blue blocks are Body blocks (representing links), and green blocks are revolute joints, with joint sensors and actuators. There is also a PD (Proportional-Differential) controller for each join.

\subsection{Ground contact}

The coordinate system in the simulator is in the beginning directly linked to the neutral point in the frame $(0,0,0)$, meaning that the robot starts with a preset body height directly centered above the zero frame point. The legs of the robot are connected to the body frame and to the robot's coordinate system. On the contrary, the feet of the robot are observed in the world coordinate system to determine the world $z$. If the $z$ is zero or smaller than zero it means that there is a contact with the ground and the forces of the ground should reflect to the feet, as shown in Figure 13. The ground is modeled as a spring-damper contact. The values for the spring and damper are Kcontact $=15 \mathrm{~N} / \mathrm{m}$ and Dcontact $=5 \mathrm{Ns} / \mathrm{m}$. The crab can stand at the ground at level $z=0$. Only when the leg is in contact with the ground do the reaction forces act on the leg (see Figure 13, red subsystem block).

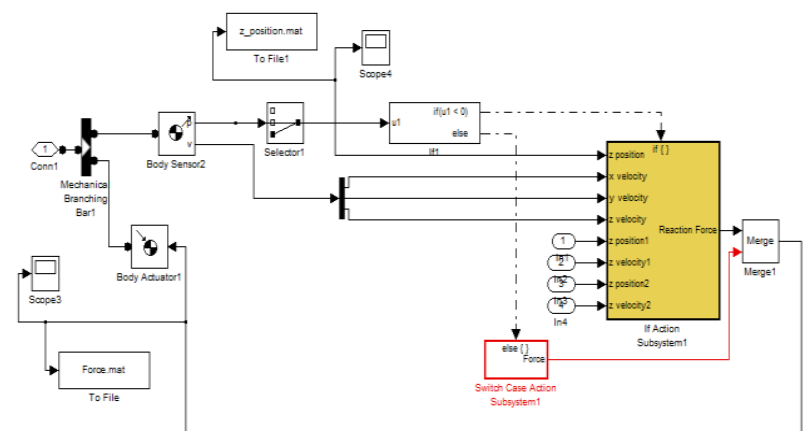

Figure 13. SimMechanics implementation of the ground contact model, which determines if the leg is on the ground or in the air and the corresponding contact force

In order to let the robot walk in a given direction, friction has to be introduced when the feet touches the ground, according to equation (2).

$$
\begin{aligned}
& F_{n}=\left\{\begin{array}{l}
-z \cdot K_{\text {contact }}-\dot{z} \cdot D_{\text {contact }} \\
0
\end{array}\right. \\
& \text { if } z \leq 0 \text {, otherwise } \\
& F_{w x}=\left\{\begin{array}{l}
-\left(2 /\left(1+e^{-10 x}\right) \mu \cdot F_{n}\right) \\
0
\end{array}\right. \\
& F_{w y}=\left\{\begin{array}{l}
-\left(2 /\left(1+e^{-10 \dot{y}}\right) \mu \cdot F_{n}\right) \\
0
\end{array}\right. \\
& \text { if } z \leq 0 \text {, otherwise } \\
& \text { if } z \leq 0 \text {, otherwise }
\end{aligned}
$$

Basically $F w=V \mu F n$, with $F n=-z \cdot K_{\text {contact }}-\dot{z} \cdot D_{\text {contact }}$, being $V$ a Sigmoid step function $2 /\left(1+e^{-10 x}\right)$, depending of the contact speed but with a $(0,0)$ crossing.

\subsection{Discrete-positional control of the crab in Simulink}

Let us consider the structure of the control subsystem (see Figure 14). The input signals (except for control signals) are combined through a multiplexer and fed to the input subsystem functional analysis of the current mismatch and terminal coordinates. The control signal is supplied to the unit of comparison, that analyzes the enabling or disabling of the sensor interrogation procedures, etc. If the signal is equal to +1 , the job passes to the next subsystem. If the signal is zero, then no change occurs in the system. 


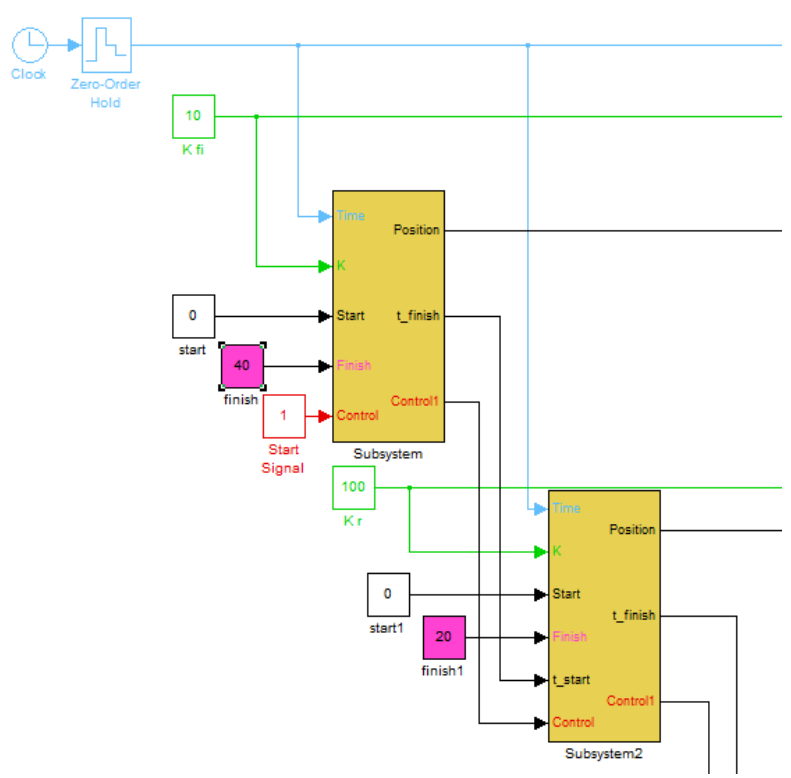

Figure 14. The integrated simulation model of the motion control of the start point

To confirm the objectivity of the model, this system was connected to the model of the robot, which was made in SimMechanics. Simulation results are presented in the next section.

\section{Model Simulation}

This section presents the results of several simulation tests performed on the developed model.

\subsection{Simulation of one leg}

The first test of the mechanism model was made with only one leg (see Figure 15), to check what occurs to the entire body while the foot is in contact with the ground surface. For this test was used the three-dimensional animation functionality of SimMechanics, and also "Scope" blocks, to depict the graphics of several variables.

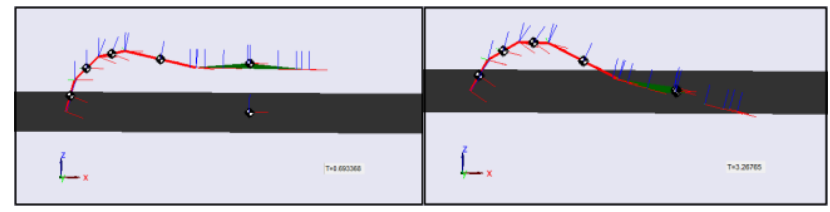

Figure 15. Simulation of the crab with one leg

These pictures show that the mechanism is working properly. There is a leg contact with the ground, and the leg does not go through the surface. Forces acting on the leg make the body move and fall down on the surface. This is normal, and the result was expected, because the crab's body is standing just on one leg and there is no support.
The plots depicted in Figure 16 show the movement of the body in the $x, y$ and $z$ axis. $Z$ position (red line) shows that the body, actuated by the gravity force, moves from the position $50 \mathrm{~mm}$ and falls down to the ground.
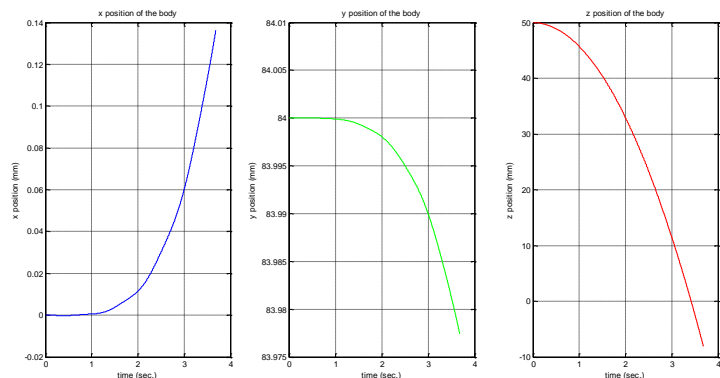

Figure 16. Plots of the $x, y$ and $z$ positions of the crab's body during simulation with just one leg

\subsection{Simulation of the spider crab locomotion}

The pictures depicted in Figure 17 are screenshots of the simulation of the spider crab locomotion during 10 seconds. In this case, the model of the crab has eight legs, four on the left side and four on the right side. The legs are positioned in relation to the body, according to their positions on a real spider crab. The pictures show the movements of the legs, and body, relatively to the surface. For this simulation were used amplitudes of motion of the segments equal to the ones that were measured in laboratory and was implemented the same locomotion movement of the leg. In Figure 17 it is possible to see that the center of mass of the crab moves against the center of mass of the ground.

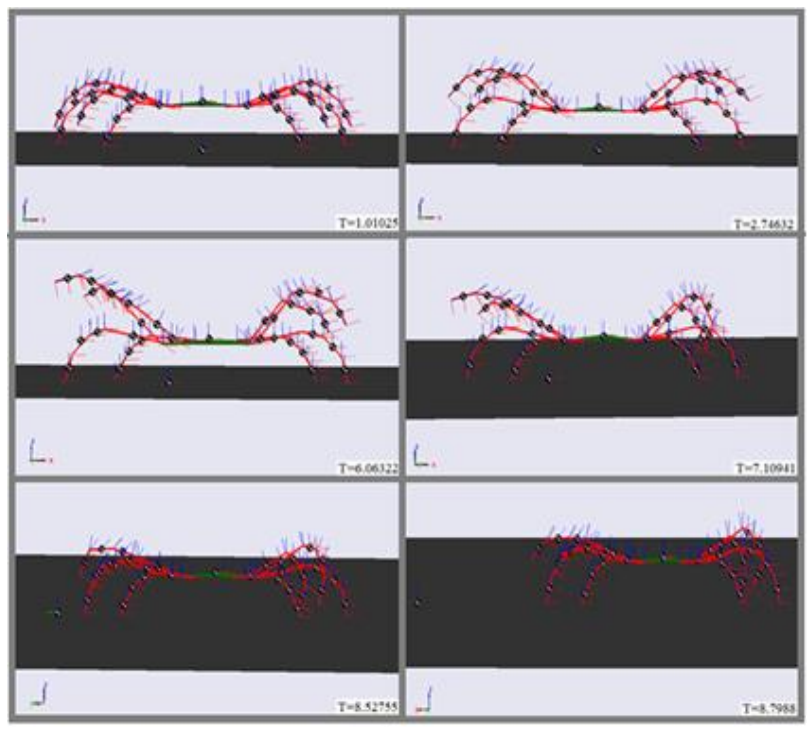

Figure 17. Simulation of the spider crab $(0-10 \mathrm{sec})$

There are four main moving legs, namely $L_{4}, L_{2}, R_{2}$ and $R_{3}$. While these legs are moving (transfer phase), the other legs are being used as a support for the body (support phase), but they are also moving with the entire body. This 
conclusion has been made studying the crab locomotion, and through the analysis of the chronograms.

The force plot presented in Figure 18 shows that there are forces acting on the leg during its motion, being the maximum value $0.9 \mathrm{~N}$. To get this plot the "Scope" was connected to the lower extremity ("foot") of the moving leg $\left(L_{4}\right)$. Theoretically the ground reaction force should be about $0.6 \mathrm{~N}$, because the crab's body weight $(526,7 \mathrm{~g})$ is equally distributed in all contact points (eight legs).

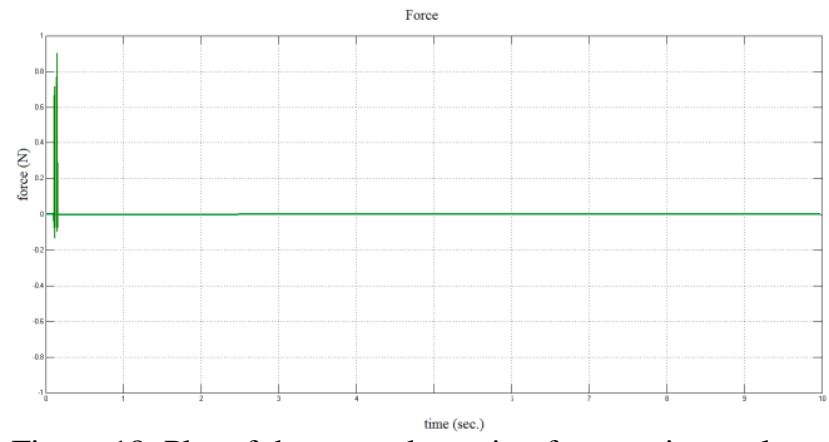

Figure 18. Plot of the ground reaction force acting on leg $L_{4}$

Figure 19 presents the plot of the reaction force acting on leg $L_{3}$. During the 10 seconds simulation, this leg is a supporting leg. The ground reaction force acting on the leg $\left(L_{3}\right)$ has the highest value of $0.3 \mathrm{~N}$.

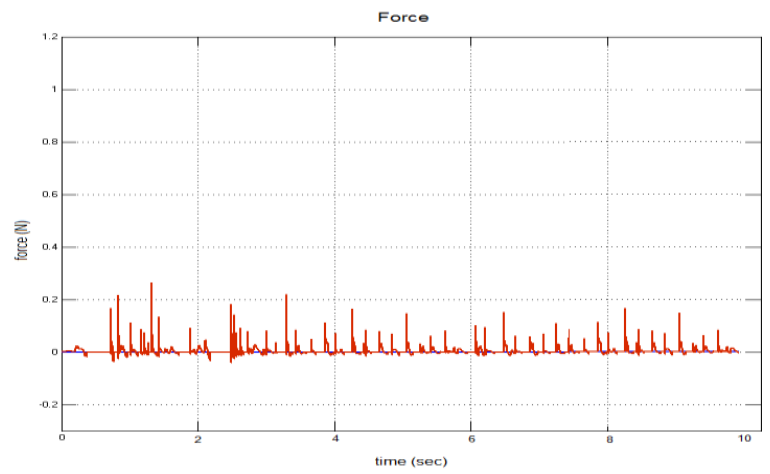

Figure 19. Plot of the ground reaction force acting on leg

$L_{3}$

In Figure 20 it is presented the $z$ coordinate of the foot of leg $L_{4}$. It is possible to conclude that there is ground contact only in the beginning of the simulation. The scope is connected to the distal part of the leg, and from this plot it is possible to see the trajectory of the moving leg.

The $z$ coordinate of the leg $L_{3}$ is presented on the chart of Figure 21. In this case the scope was also connected to the distal end of this leg. This leg is not moving during the simulation, but actuated by the forces the leg penetrates slightly into the ground and then raises above the ground just less than $0.0005 \mathrm{~mm}$, as can be seen from the plot.

During this simulation the crab moves. On Figure 22 are presented plots of the crab's $x, y$ and $z$ body position (blue is $x$ axis, $y$-green and red is $z$ axis).

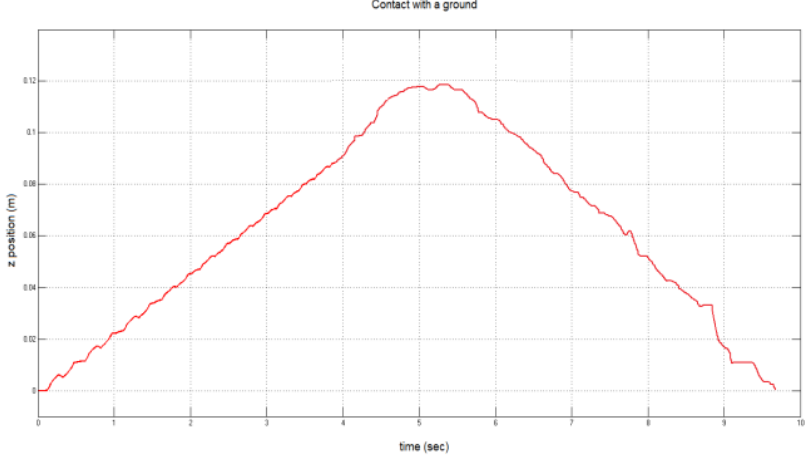

Figure 20. Plot of leg $L_{4}$ foot $z$ position during simulation

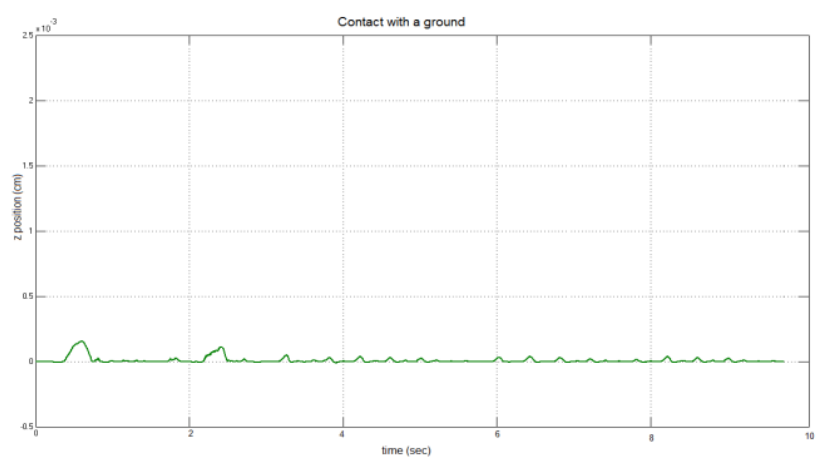

Figure 21. Plot of leg $L_{3}$ foot $z$ position during simulation
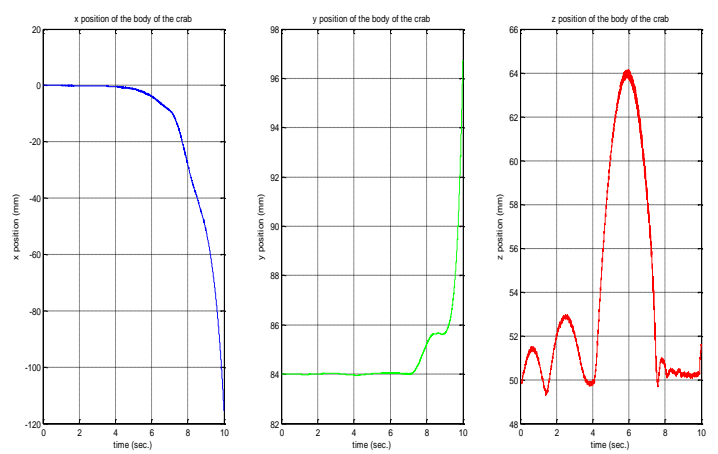

Figure 22. Plots of $x, y$ and $z$ positions of the crab's body during simulation

\section{Conclusion and Perspectives for Future Developments}

\subsection{Conclusion}

The main idea behind this work is to gain knowledge of biological beings that evolved over millions of years, and apply this knowledge in practice, in robotics design.

In this paper, is presented the modeling, simulation and control of the spider crab, which might be an option for a new type of biologically inspired robot. The strategy has been to use the animal's kinematic and dynamic characteristics and behavior as the default in the design and control of a robot model. 
In laboratory were measured the parts of its body, was studied the locomotion and trajectory of the crab movements, to implement a more realistic, and based on real data, simulation model. The crab model was implemented and programmed in Matlab/SimMechanics and in SolidWorks. The legs are all individual controlled, but the robot legs are not equally constructed in shape, size and mass. In the dynamic environment, gravity and mass are affecting the model. Model parameters (mass, length, diameter, motion amplitudes) are the same as the ones of the real crab. The kinematic model has been slightly changed, to make a model less complex, without significantly changing the biomechanical properties of the Spider Crab. The dynamic model has a ground contact model implemented in order to make the robot stand on the ground surface. This model is implemented to give the feet a reaction force to the ground, and to make the robot move in the desired direction was used a discretepositional control system. Closer attention was given to the spider crab's biology and biomechanical aspects in the design of this robot model. Concerning the locomotion, the algorithm presented in this paper allows the crab to walk sideways. As a result, a robot model that is moving in an "animal like" manner was obtained.

\subsection{Perspectives for future developments}

To further develop the simulation programs described in this paper towards a realistic spider crab model, the following development steps are needed:

- To achieve higher walking speeds it is necessary to investigate the dynamic algorithms;

- Tune the PD controller parameters for each leg joints, to make the model walk with better performance and faster;

- Design an algorithm for the general path planner in order to make the robot walk according to a desired trajectory;

- In the future it is necessary for the robot to climb on the rocks, walk on the sand surface, and enter to the water, as a real spider crab does. These extra features will reduce the stability of the robot, so it is necessary to investigate dynamic stability algorithms;

- The development of a real robot biologically inspired in the "Maja brachydactyla", will be the final objective for future work.

\section{Acknowledgements}

Thanks to ELA and Professor Mike Weber for providing the laboratory, material and tools to studying crabs, and for permission to film the crabs and take photos inside the aquarium. Thanks are also due to Professor João Pinho, for help with SolidWorks, and to Dra. Marta Rufino, Prof. Fernando Carvalho, Prof. Paulo Vaz-Pinto and Dra. Sara Barrento for supplying useful information about crabs.

\section{References}

[1] Birch, M. C., Quinn, R. D., Hahm, G., Phillips, S. M., Drennan, B., Fife, A., Verma, H. and Beer, R. D., Design of a Cricket Microrobot. Proc. of the IEEE Int. Conf. on Rob. \& Aut., San Francisco, CA, USA, 2000, 1109 1114.

[2] Mederreg, L., Hugel, V., Bonnin, P., Blazevic, P., Abourachid, A. and Stasse, O., The RoboCoq Project Modeling and Design of Bird-Like Robot Equipped With Stabilized Vision. Proc. CLAWAR'2003 - 6th Int. Conf. on Climbing and Walking Robots, Catania, Italy, 2003, $761-768$.

[3] Kajima, H., Doi, M., Hasegawa, Y. and Fukuda, T., Study on Brachiation Controller for the MultiLocomotion Robot - Redesigning Behavior Controllers. Proc. of the 2003 IEEE/RSJ Int. Conf. on Intelligent Robots \& Systems, Las Vegas, Nevada, USA, 2003, 1388 $-1393$.

[4] Davis, S., Tresadern, P., Canderle, J., Tsagarakis, N. G., Dodd, P. and Caldwell, D. G., The Biomimetic Design of 'Soft' Mechatronic Systems. Proc. of the ICAR 2003 11th Int. Conf. on Advanced Robotics, Coimbra, Portugal, 2003, $720-725$.

[5] Peng, S., Lam, C. P. and Cole, G. R., A Biologically Inspired Four Legged Walking Robot. Proceedings of the 2003 IEEE Int. Conf. on Rob. \& Aut., Taipei, Taiwan, 2003, $2024-2030$.

[6] Hennion, B., Pill, J. and Guinot, J.-C., A Biologically Inspired Model For Quadruped Locomotion. Proc. CLAWAR'2005 - 8th Int. Conf. on Climbing and Walking Robots, London, U.K., 2005, 49 - 56.

[7] Ayers, J. and Witting, J., Biomimetic approaches to the control of underwater walking machines. Philosophical Transactions of the Royal Society, Series A, accepted for publication, 2006.

[8] The European Spider Crab Biology and Fishery http://www2.hawaii.edu/ carlm/spider.html; Last access: October 30, 2012.

[9] R. Rynkevic, M. F. Silva, A. M. Marques. Biomechanical Modeling and Simulation of the Spider Crab (Maja Brachydactyla). Submitted to the 7th Int. Conf. on Bio-Inspired Models of Network, Information, and Computing Systems, Lugano, Switzerland, 2012.

[10] Биомеханика ходьбы;

http://spinet.ru/conference/post56043.html; Last access: October 19, 2012.

[11] Отряд ракообразные десятиног; (decapoda); http://www.floranimal.ru/orders/6966.html; Last access: October 19, 2012.

[12] Евдокимов Ю.И., Структура механизмов. основные понятия и определения (Новосибирск,2009). [13] Дьяконов В.П., MATLAB 6/6.1/6.5 + Simulink 4/5 в математике и моделировании. Пол-ное руководство пользователя (М.: СОЛОН-Пресс, 2003)

[14] Simmechanics.

http://www.mathworks.com/products/simmechanics/, january 2010; Last access: October 19, 2012. 